\title{
Correction to: Acid Suppressant Therapy: a Step Forward with Potassium-Competitive Acid Blockers
}

\section{Carmelo Scarpignato ${ }^{1,2,3, *}$ 。 Richard H. Hunt ${ }^{4}$}

\author{
Address \\ *,1 United Campus of Malta, Msida, Malta \\ Email: carmelo.scarpignato@gmail.com \\ ${ }^{2}$ Faculty of Medicine, Chinese University of Hong Kong, Hong Kong, Hong Kong \\ ${ }^{3}$ University of Nantes, Nantes, France \\ ${ }^{4}$ Department of Medicine, Division of Gastroenterology and Farncombe Family \\ Digestive Health Research Institute, McMaster University, Hamilton, 0N, Canada \\ Published online: 11 March 2021 \\ (C) Springer Science+Business Media, LLC, part of Springer Nature 2021
}

The online version of the original article can be found at https://doi.org/10.1007/s11938-020-00330-x

\section{Correction to: Curr Treat Options Gastro https://doi.org/10.1007/s11938-020-00330-x}

The article Acid Suppressant Therapy: a Step Forward with Potassium-Competitive Acid Blockers, written by Carmelo Scarpignato and Richard H. Hunt, was originally published electronically on the publisher's internet portal on January 25, 2021 without open access. With the author(s)' decision to opt for Open Choice the copyright of the article changed on February 22, 2021 to ${ }^{\odot}$ The Author(s) 2021 and the article is forthwith distributed under a Creative Commons Attribution.
The original article has been corrected.

\section{Publisher's Note}

Springer Nature remains neutral with regard to jurisdictional claims in published maps and institutional affiliations. 